\title{
The Cause of the Gleissberg Cycle: A Working Hypothesis
}

\section{Sebastián Martín Ruiz}

Avda. De Regla, Chipiona, Spain

Email: smruizg@gmail.com

Received 2 December 2015; accepted 16 December 205; published 22 December 2015

Copyright (C) 2015 by author and OALib.

This work is licensed under the Creative Commons Attribution International License (CC BY).

http://creativecommons.org/licenses/by/4.0/

(c) (i) Open Access

\begin{abstract}
Gleissberg cycle is a recurring climatic period of 80 years duration. It is usually attributed to the influence of the Sun. In this article, we present a new hypothesis for the possible cause related to the magnetic field of Jupiter.
\end{abstract}

Keywords

Gleissberg Cycle, Maunder Minimum, Cosmic Rays, Jupiter's Magnetic Field

Subject Areas: Modern Physics

\section{Introduction}

The Gleissberg cycle (Figure 1) is a 80-year climatic cycle which causes climatic cycle [1] the famous Maunder Minimum (Figure 2) that apparently originates the Little Ice Age. The intensity variation of this cycle is more or less the same order as the solar cycles of 11 years but with the difference that occurs in a longer period of time sufficient to make significant climatic changes.

The Gleissberg cycle may be the main cause of these variations in global temperatures.

\begin{tabular}{lll}
\hline Medieval Warm Period & 1100 & 1250 \\
Wolf Minimum & 1280 & 1350 \\
Sporer Minimum & 1450 & 1550 \\
Maunder Minimum & 1645 & 1715 \\
Dalton Minimum & 1790 & 1820 \\
Modern Maximum & $1900-$ & \\
\hline
\end{tabular}

How to cite this paper: Ruiz, S.M. (2015) The Cause of the Gleissberg Cycle: A Working Hypothesis. Open Access Library Journal, 2: e2203. http://dx.doi.org/10.4236/oalib.1102203 


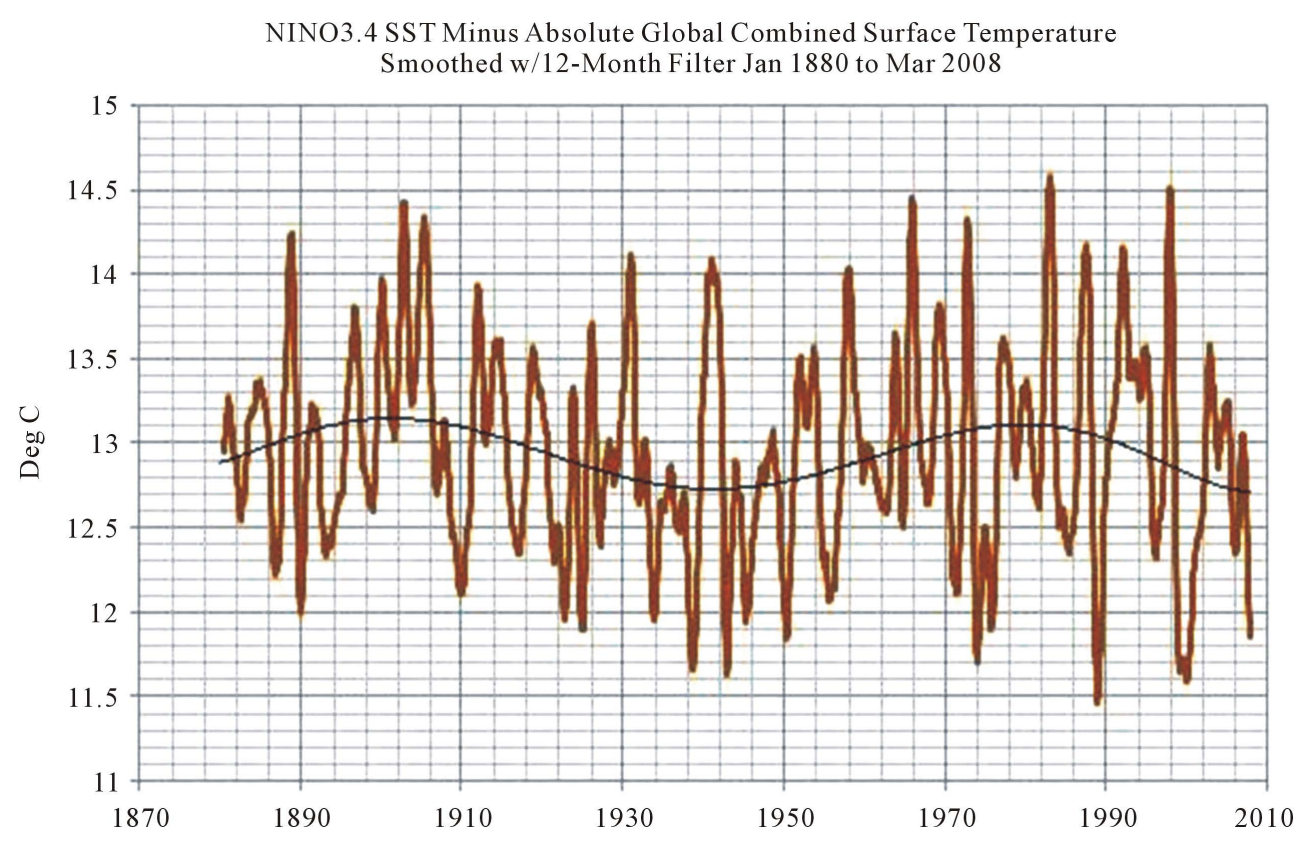

Figure 1. The smooth curve of temperatures between 1880 and 2010 has sinusoidal shape and its maximum is about 1900 and 1980 therefore it has a period of approximately 80 years.

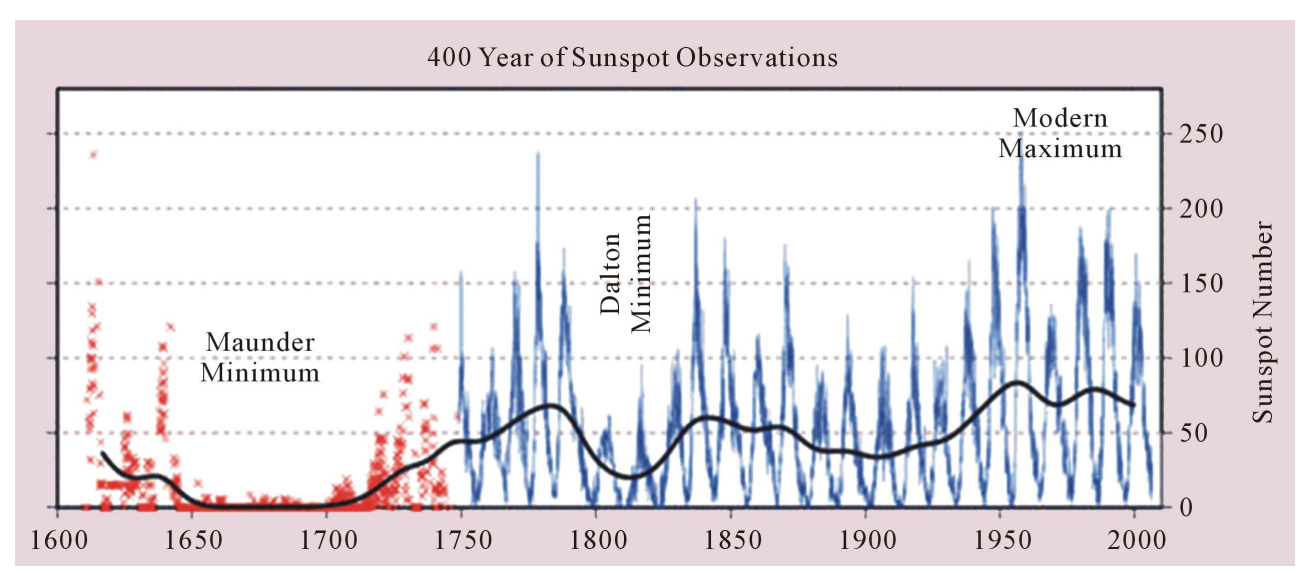

Figure 2. The Maunder Minimum occurred between 1645 and 1715.

The Gleissberg cycle is usually attributed to a solar activity cycle. But we think it may have another possible, cause.

\section{Cosmic Rays}

Anyway we should consider the recent research on the influence of the cosmic rays on the weather.

The scientist Henrik Svensmark [2] [3], director of the Research Center of the Sun-Climate Relationship was surprised "by the speed and efficiency of how the electrons work to create the main blocks for the cloud condensation nuclei".

The results of this experiment supports the empirical theory proposed a decade ago (made by scientists Henrik Svensmark and Eigil Friis-Christensen), that cosmic rays influences the Earth's climate through cloud formation (Figure 3). The original theory showing the correlation between the change in the intensity of cosmic rays entering our atmosphere and the amount of clouds located at a low altitude. Cloud cover increases when the cosmic ray intensity increases and decreases when the intensity declines.

It is known that low-altitude clouds have a cooling effect on the Earth's surface so that variations in cloud 


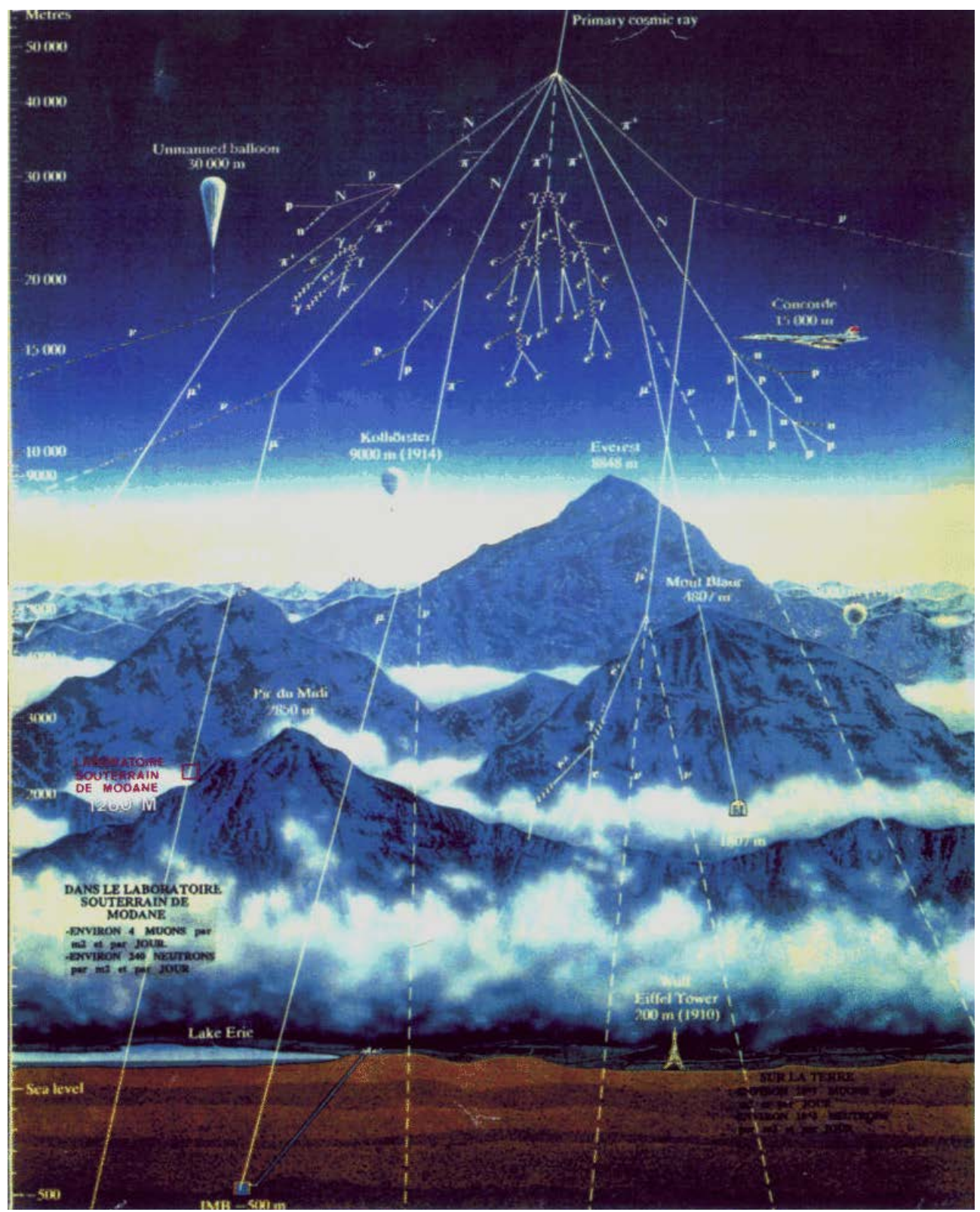

Figure 3. Cosmic rays influence the creation of clouds.

covering caused by cosmic rays could, in turn, change the temperature of the surface.

The existence of this connection between cosmic rays and the Earth's climate could explain past and present variations of our climate.

\section{The Possible Effect of Jupiter}

We should wonder what can produce a 80-year cycle in cosmic radiation reaching the Earth. To vary the cosmic radiation striking the Earth in a 80-year cycle, we would need to have a magnetic shield that rotates against the background of fixed stars every 80 years or so. Well, we have it. It is the planet Jupiter [4]-[6], although its visible radiation from the Earth is small, we all know that it has a magnetic field (Figure 4) as seen from Earth is greater than the full Moon. This could be deflecting the cosmic radiation coming from outside the solar system. And the position of Jupiter, seen from Earth, as regards to the fixed stars varies precisely in a period of approximately 80 years [7]. This is because the orbital period of Jupiter is 11.86 years and $11.86 \times 7=83.02$. Every 83 


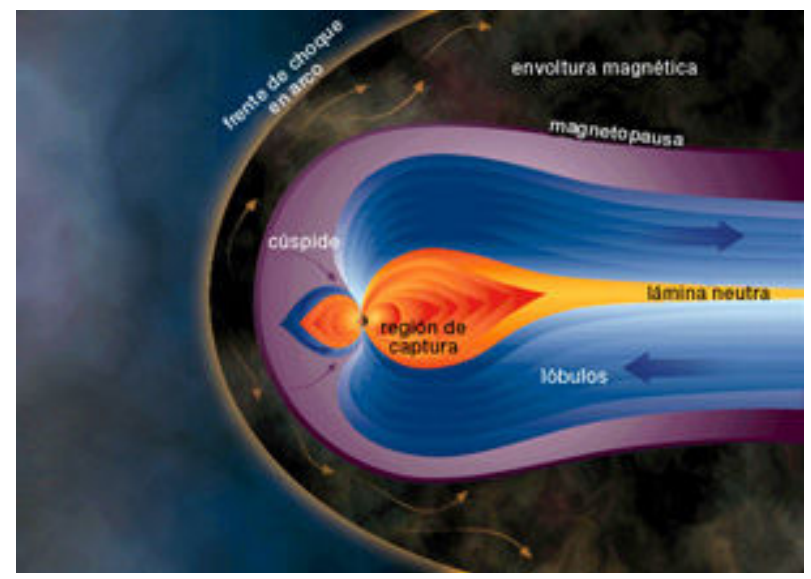

Figure 4. Jupiter's magnetic field is much larger than the planet already giant.

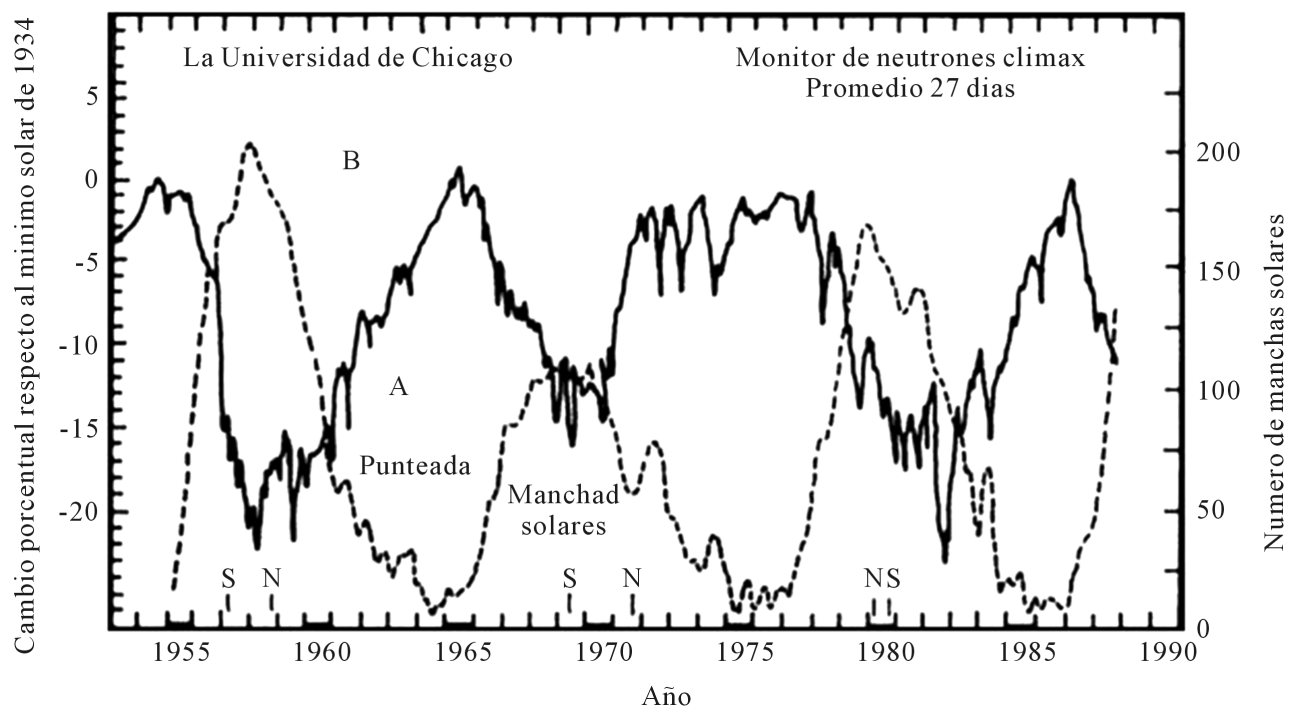

Figure 5. Intensity of cosmic radiation (solid line) from 1953 to date detected in the monitor climax, United States, along with the sunspot cycle (dotted line) for the same period.

years, Jupiter and the Earth are in the same relative position in the Solar System and this way Jupiter is seen against the same background of stars.

According to this hypothesis it would be interesting to study the frequency of radiation coming from outside the solar system like the solar [8]-[11] radiation that correlates [12] with sunspots (Figure 5).

\section{Conclusion}

In conclusion, we think that the influence of Jupiter's magnetic field on cosmic rays reaching the Earth and its relationship to Earth's climate should be investigated.

\section{References}

[1] (2011) Historia de los cambios climáticos. Comellas Garcia Llera, Jose Luis (RIALP).

[2] (2003) The Chilling Stars: A New Theory of Climate Change by Henrik Svensmark and Nigel Calder.

[3] (2004) The Chilling Stars: A Cosmic View of Climate Change by Henrik Svensmark and Nigel Calder.

[4] Rogers, J.H. (1995) The Giant Planet Jupiter. Cambridge University Press, Cambridge.

[5] Bagenal, F., Dowling, T.E., McKinnon, W.B., Jewitt, D., Murray, C., Bell, J., Lorentz, R. and Nimmo, F. (2004) Jupi- 
ter: The Planet, Satellites and Magnetosphere. Cambridge University Press, Cambridge.

[6] Sagan, C. (1961) El Sistema Solar. Blume-Hermann, Madrid.

[7] Fernando Beltrán Postigo: Personal Communication: Investigation of Orbital Period of Jupiter. https://www.youtube.com/user/fernandobeltranp

[8] de Madrid, A.A. (1998) Manual de Astronomía Práctica. Agrupación Astronómica de Madrid.

[9] Astronomía. COMELLAS, JOSE LUIS. Sevilla. Rialp 1987.

[10] Estrellas. HERRMANN, J. Barcelona Blume 1986.

[11] (1994) El Sol: Nuestro astro. II Curso de Introducción a la Astronomía. HIDALGO RODRIGUEZ, INÉS (CICCAIAC).

[12] http://bibliotecadigital.ilce.edu.mx/sites/ciencia/volumen3/ciencia3/108/htm/sec_10.htm 